Fire and Ice - Safety, Comfort, and Getting the FireFighters' Job Done

\author{
Tico Foley \\ NASA, Johnson Space Center \\ Houston, Texas
}

\author{
Melissa Butzer \\ Oceaneering Space Systems \\ Houston, Texas
}

\title{
ABSTRACT
}

Daily life for firefighters consists of working with life-threatening hazards in hostile environments. A major hazard is excessive ambient heat. New hazards have arisen from protective gear that was intended to increase survival time of firefighters while finding and rescuing victims. The insulation is so good now that a firefighter's metabolic heat buildup cannot escape. This forces body core temperatures to life threatening levels in about 20 minutes of moderate activity. Using NASA space suit technology, Oceaneering Space Systems developed a liquid cooling garment prototype that will remove up to 250 watts of metabolic heat. After testing and certification as an approved accessory for firefighter use, this garment will be available for use by any individual encapsulated in protective clothing. This demonstration will present a high surface area circulated liquid cooling garment displayed on a mannequin and available for attendees to try on to experience the effects of active cooling. 


\section{Fire and Ice - Safety, Comfort, and Getting the FireFighters' Job Done}

\author{
Tico Foley \\ NASA, Johnson Space Center \\ Houston, Texas
}

\author{
Melissa Butzer \\ Oceaneering Space Systems \\ Houston, Texas
}

This demonstration will present a high surface area circulated liquid cooling garment for use by firefighters and others encapsulated in protective clothing. The garment will be displayed on a mannequin and available for attendees to try on in order to experience the effects of active cooling.

Get out your parents' or grandparents' old coloring book and look at the pictures of firemen at work. What has changed in the protective clothing and equipment of the firemen since the first half of this century? How have these changes improved the working conditions and job effectiveness of today's firefighter? Every year, thousands of fire-related deaths and hundreds of thousands of injuries remain at very high levels for firefighters and civilian fire victims; total dollar costs from fire loss exceed a hundred billion dollars annually. In a structural fire, what are the critical barriers to effective search and rescue operations? The primary goal of the first firefighters on a scene is to go into the fire to find and bring out any survivors; only then can the firefighter focus on preserving property. What are the design drivers that limit the endurance allowed a firefighter in performing the life-saving job?

Two Houston Fire Department captains approached the National Aeronautics and Space Administration (NASA) Johnson Space Center (JSC) with a blackened and blistered helmet in their hands. All they wanted was some help in finding a material that would do a better job of protecting their coworker on the job when he got out of the hospital. His suit had not protected him in a two-story apartment fire when flash-over conditions (temperatures typically hotter than $1100^{\circ} \mathrm{C}\left(2000^{\circ} \mathrm{F}\right)$ ) gave him deep burns to his head, neck, shoulder, and thigh. As the firefighters told their story, a team of NASA engineers found that there were several dozens of areas where space suit technologies and rocket science techniques could offer possible suit improvements. One of the NASA engineers is also a volunteer firefighter, and he added accounts of firefighters being overcome by heat exhaustion before they even reached the fire. This is the story about how we came to develop a cooling garment prototype for firefighters.

In the days when firemen were justifiably called "smoke eaters," their protective garments were thick layers of leather, wool, and asbestos. They had no protection for their faces; they got steam and ember burns where clothing components met; radiation heat boiled them in their own sweat; and they breathed smoke. Then, their working duration was limited by the lack of breathable air. In the 1970s, NASA JSC helped develop reinforced air tanks that allow an air supply rated at 30 or 60 minutes of normal breathing. Improved fabrics now can insulate firefighters from $150^{\circ} \mathrm{C}$ to $250^{\circ} \mathrm{C}\left(300^{\circ} \mathrm{F}\right.$ to $500^{\circ} \mathrm{F}$ ) ambient temperatures for 15 or 20 minutes. New fibers are being developed and tested that will withstand even greater temperatures and thermal radiation. Now, the insulation is so good, that the limiting factor for firefighter endurance is the 
metabolic heat load that builds up inside the firefighter suit, raising core body temperatures to life threatening levels within 15 to 20 minutes. More than half the firefighter deaths on the job each year come from heat stress and heart attacks, not from burns.

Current space suits are designed to insulate an astronaut in an environment that can be minus $125^{\circ} \mathrm{C}\left(-200^{\circ} \mathrm{F}\right)$ on the shady side and positive $100^{\circ} \mathrm{C}\left(200^{\circ} \mathrm{F}\right)$ on the sunny side. Work activity within the space suit has been measured at levels in excess of 500 watts (a normal human working at a desk produces about 100 watts). So the astronaut, like the firefighter, gets pretty warm inside the suit, regardless of the outside temperature. To cool the astronaut, the space suit ensemble includes an undergarment that is laced with plastic tubes that carry chilled water. This cooling approach has been used by NASA JSC to develop a cooling undergarment so that children who are super sensitive to ultraviolet radiation can wear a protective coverall and go outside to play.

Firefighter clothing and accessories must meet heat and flame resistance standards established by the National Fire Protection Association (NFPA). Oceaneering Space Systems (OSS) had been working on a cooling garment for hazardous materials cleanup crews to wear under their protective outer garment. NASA has teamed with OSS to select fabrics for the structure of the cooling garment, plastic tubing and patches, and connectors. NASA is currently testing the firefighter version of the liquid cooling garment for its impact on reach limits and work envelope in much the same way that astronaut space suits are tested for their usability.

The OSS cooling garment is based on NASA's original research in liquid cooling garments as a solution to metabolic heat buildup. However, the application of the technology had to change to meet the cost and durability requirements of hazardous materials (hazmat) workers and firefighters. The solution was to build a highly efficient cooling garment using a combination of bladders and tubing rather than just tubing. This combination provides substantial surface area for the cooling liquid to remove heat from the skin surface. The increased surface area also allows the garment to operate effectively at a warmer water temperature, which decreases power consumption on the chilling units and increases user comfort by decreasing the likelihood of vasoconstriction. Chilled liquid can be supplied to the cooling garment by several methods, provided an appropriate temperature and flow rate is produced. Currently, the cooling garment has been paired with a liquid air breathing apparatus that provides breathing air and cooling liquid. A simpler but effective alternative obtains the cool water from an ice based chiller system.

The current firefighter cooling garment prototype will be undergoing further tests for fit and comfort, usability, cooling efficiency, and adherence to the NFPA standards. We are still at the applied research level in developing this prototype liquid cooling garment, but already we know that a firefighter can walk around in the broiling Houston sun, while fully enclosed in the firefighter turnout gear, and still maintain a safe core temperature for several hours. 
Perhaps the major obstacle to be overcome, as with any new firefighter technology, is implementing the acceptance of a liquid cooling garment among firefighters.

Paradigm shifts are resisted on many fronts. Some are practical arguments about costs versus benefits: dollar costs are perceived to be greater; weight is increased and mobility decreased; increased complexity suggests that more things can go wrong; sensory inputs are impaired; and so on. In addition, there are psychological factors that are expressed as challenges: "real firefighters don't need that" and "it was good enough last fire, why should we change the equipment and procedures?"

Improvements in protective clothing have changed the way firefighters must work and think. The new technologies, such as the self-contained breathing apparatus and well encapsulated insulated garments, have kept the firefighter from breathing toxic fumes and prevented many routine burns. Meanwhile firefighters say they have lost touch with their environment. Their noses can no longer be used to distinguish among, and orient from, the smells of smokes and steams. Their necks don't warn them that it is quickly getting too hot and the place is approaching flashover conditions.

The liquid cooling garment will add weight, but if the firefighter avoids heat stress, then there will be less total exertion due to decreased cardiac stress. Wearing protective clothing that includes an accessory of a liquid cooling garment will cost more dollars for each firefighter so equipped, but each of those firefighters will have more time and energy to save a life. Another protective layer will further impair mobility and further remove the firefighter from situation awareness, but other technologies and accessories are being developed and will be implemented to overcome these obstacles.

At NASA JSC the goal is to apply space technology products and processes to develop an integrated but modular firefighter suit. The liquid cooling garment is but one step in a multi-block approach to address the firefighter protection and productivity issues as a system. Members of the NASA JSC FireFighter Suit and Gear Team are addressing alternatives, including the design of a helmet that will incorporate built-in digital quality communications with noise canceling headsets, clothing elements to reduce burns from compressed insulation and injuries from structural collapse, built-in sensors and imaging devices to help the firefighter and scene commander evaluate the fire environment as well as continuously monitor the health status of each individual firefighter. The science and technology exists; it is past time to bring the firefighter protective gear into the twentieth century.

Our children will have coloring books showing firefighters who look more like space-suited astronauts. Fortunately, the marketplace shows that kids are not restricted by old paradigms. Glow-blue and fluorescent yellow-green crayons are as accepted as red crayons. There will be no penalty for coloring outside the lines in order to push the design into the next century. 